\title{
"Quem Nunca Teve Origem Não Volta": o direito da autodeclaração e seus impasses no acesso às vagas para indígenas no Ensino Superior ${ }^{*}$
}

"Who Never Originated Never Comes Back": the right of self-declaration and its impasses in accessing places for indigenous people in higher education

\author{
Ana Caroline Amorim Oliveira ${ }^{1}$ \\ ${ }^{1}$ Universidade Federal do Maranhão, São Luís, MA, Brasil
}

* O presente artigo é uma parte da tese intitulada "A Caneta é nossa Borduna": um estudo etnográfico sobre as experiências indígenas Tenetehara/Guajajara no ensino superior no Maranhão defendida em 2018. Agradeço pelas considerações dos pareceristas sobre o presente artigo. 


\section{Resumo}

O objetivo deste artigo consiste em refletir sobre a autodeclaração como critério para a ocupação de vagas pelos povos indígenas no ensino superior público e os debates que tal critério gera acerca da indianidade. O critério de autodeclaração, presente na Lei de Cotas 12.711/2012, produziu um debate acerca da indianidade para as instituições universitárias que se veem diante do imperativo de ter que lidar com a indianidade nas suas burocracias produzindo, por consequência, um inflacionamento da identidade indígena sem levar em consideração os critérios nativos de pertencimento às comunidades. O contexto da reflexão é o processo de construção de comissões para garantir as vagas para indígenas na Universidade Federal do Maranhão (UFMA) sob pressão das lideranças indígenas, em especial, do povo Tenetehara/Guajajara. Nesse embate, entre os tenetehara e a burocracia estatal, o idioma da guerra reaparece refletindo a resistência dos ameríndios em relação à tentativa constante de desindianização por parte do Estado.

Palavras-chave: Lei de Cotas. Autodeclaração. Povos Ameríndios. Tenetehara/Guajajara.

\section{Abstract}

The purpose of this article is to reflect on self-declaration as a criterion for the occupation of vacancies by indigenous peoples in public higher education and the debates that such criterion generates about indianness. The selfdeclaration criterion, present in Quota Law 12.711/2012, has produced a debate about indianness for university institutions that face the imperative of having to deal with indianity in their bureaucracies, thus producing an inflation of indigenous identity without regard to the native criteria of community membership. The context of the reflection is the process of building commissions to guarantee vacancies for indigenous people at the Federal University of Maranhão (UFMA) under pressure from indigenous leaders, especially the Tenetehara/Guajajara people. In this clash, between the tenetehara and the state bureaucracy, the language of war reappears reflecting the resistance of the amerindians to the state's constant attempt to "desindianização".

Keywords: Quota Law. Self Declaration. Amerindian Peoples. Teneteharal Guajajara. 


\section{Introdução}

objetivo do presente artigo é realizar uma reflexão sobre a utilização da autodeclaração como critério para a ocupação de vagas pelos povos indígenas no ensino superior público e sobre os debates que tal critério gera acerca da indianidade.

Tal debate foi produzido em virtude das instituições universitárias que se veem diante do imperativo de ter que lidar com a indianidade e suas diferenças potenciais nas suas burocracias. Produzindo, em alguns casos, um inflacionamento da identidade indígena não considerando os critérios das próprias comunidades. A autodeclaração é compreendida como um direito conquistado pelos povos tradicionais por garantir o direito do próprio grupo ou membro do grupo de se autoidentificar, não passando pela mediação de nenhum órgão ou país interferindo no pertencimento identitário nativo.

Entretanto, ao se tornar um critério legal dentro de uma política de ação afirmativa para os indígenas, isto é, de fora para dentro, surgem outros questionamentos: quais as consequências desse critério para os povos indígenas, em particular, os tenetehara/guajajara? Quais as consequências identitárias para os povos que passaram por processos de massacres e extermínios e que agora devem demonstrar ao Estado uma continuidade da existência de suas coletividades? Como os diferentes povos indígenas estão articulando tal critério de autodeclaração para poder acessar a universidade? Enfim, ao supostamente reconhecer o critério legal reivindicado pelos movimentos indígenas da autoidentificação se está, de outro modo, também esvaziando as ideias nativas de indianidade dentro da lógica burocrática? 
Toma-se como campo empírico a criação das comissões para regulamentar a entrada nas vagas para indígenas que ocorreu na Universidade Federal do Maranhão (UFMA), no período de 2017 2018, sob demanda das lideranças indígenas, em especial do povo tenetehara/guajajara ${ }^{1}$ para que seus filhos, netos e sobrinhos entrassem na universidade.

Na primeira parte do artigo apresenta-se a discussão sobre o critério de autodeclaração como uma conquista dos povos indígenas. Em seguida, realiza-se um etnografia de evento (CARNEIRO DA CUNHA, 2009) sobre a construção das comissões na UFMA para a criação de critérios para as vagas para índios apresentando a compreensão dos índios tenetehara acerca da autodeclaração. E, por fim, apresenta-se as breves considerações finais.

\section{Da Conquista do Direito à Autodeclaração Identitária}

A autodeclaração identitária é um reconhecimento de um direito dos povos indígenas de se autorreconhecerem e de serem reconhecidos como coletividades específicas possuídoras de direitos coletivos. Tal noção é afirmada e garantida pela primeira vez no Brasil com a Constituição Federal de 1988 (CF-88), que traz uma mudança de paradigmas nas políticas indigenistas brasileiras até então vigentes: de um paradigma da transitoriedade dos ameríndios para um paradigma da permanência/continuidade das comunidades nativas (VIVEIROS DE CASTRO, 2005).

Como consequência, ocorre uma mudança de nomenclatura: em lugar de índio, aparece comunidade de direitos individuais e de direitos coletivos. Viveiros de Castro (2005) destaca que a CF-88 interrompe, tanto juridica quanto ideologicamente, um projeto secular de desindianização ao anunciar que ele não havia se completado e que nunca se completaria ao reconhecer a organização social, os costumes, as línguas, as crenças e as tradições dos povos nativos.

Art. 231 São reconhecidos aos índios sua organização social, costumes, línguas, crenças e tradições, e os direitos originários sobre as terras que tradicionalmente ocupam, competindo à União demarcá-las, proteger e fazer respeitar todos os seus bens. 
Na Convenção n. 169 da Organização Internacional do Trabalho sobre Povos Indígenas e Tribais (OIT, 2011), da qual o Brasil é um país signatário, usa-se o termo "autoidentificação", que é considerado critério fundamental para a definição dos grupos e de seus membros para a aplicação da própria convenção.

Carneiro da Cunha (2012a) afirma que os novos instrumentos internacionais, como a Convenção n. 169 da OIT e a Declaração dos Direitos dos Povos Indígenas da Organização das Nações Unidas (ONU), baseiam-se em uma revisão que aconteceu nos anos de 1970 e 1980 sobre as noções que guiavam o Ocidente como progresso, desenvolvimento, integração e discriminação ou racismo. Essa revisão ocorreu no contexto do pós-guerra em um momento em que a confiança naquelas noções estava abalada.

Outras categorias surgem direcionando um novo enfoque como etnodesenvolvimento, direito à diferença, valor da diversidade cultural e, dentro disso, a autoidentificação dos povos nativos nos documentos internacionais. A autora em sua análise ainda destaca que tais termos e noções suscitaram muitos dilemas, considerados por vários países como ameaças à soberania dos Estados-nação, em especial, o Brasil.

Diante disso, a própria Convenção n. 169 dissipa tal possibilidade ao afirmar que a noção de povos não interfere nos sentidos do direito internacional. Carneiro da Cunha (2012a) identifica essa ambivalência presente na Convenção n. 169 pois, ao mesmo tempo em que reconhece a autoidentificação dos povos por um lado, ele a deslegitima por outro. A autora chama de uma vulgarização do termo "povos" nos documentos internacionais. A vulgarização do termo se estende à ideia de autoidentificação dos povos nativos e, portanto, do reconhecimento de sua autonomia.

As políticas de ação afirmativa no Brasil passam a utilizar a autodeclaração identitária referente à cor/raça ou etnia/povo para acesso à universidade a partir da lei de cotas, Lei n. 12.711/2012². O que tem gerado muito embate em torno das ações afirmativas não é a autodeclaração em si, mas a entrada de pessoas não indígenas, utilizando-se da autodeclaração, e as respostas dadas pelos povos indígenas, em particular os tenetehara/guajajara, e a criação de critérios para "comprovação" da indianidade. 
Retoma-se a questão quem é índio no Brasil? que de tempos em tempos (re)aparece. A autodeclaração da indianidade inverte a questão de séculos atrás: da perda da indianidade para a explosão da indianidade; do deixar de ser índio para se tornar índio como destaca Viveiros de Castro (2005, p. 1-12):

Só que agora não é mais porque tem muito índio que ‘não é mais índio', mas porque tem muito branco que 'nunca foi índio' querendo 'virar índio'. Quando seria melhor dizer: tem muito branco, que nunca foi muito branco porque já foi índio, querendo virar índio de novo.

O critério de autodeclaração para ter acesso às vagas para índios produziu um debate sobre a indianidade para as instituições universitárias que se veem tendo que lidar com a indianidade nas suas burocracias. Vários são os casos de fraude de não índio se dizendo índio para entrar na universidade, e conseguindo entrar. Na Universidade de Brasília (UNB), estudantes que não eram índios conseguiram entrar nas vagas para indígenas por meio da identificação pela Fundação Nacional do Índio (FUNAI) junto ao MEC e pelas comunidades indígenas. Após um processo interno, os supostos indígenas foram afastados (SOUSA, 2009). ${ }^{3}$

Outra situação também presente e identificada nas universidades é a de não índios que possuem um documento de identificação da FUNAI, o Registro Administrativo de Nascimento Indígena (RANI). Como alertam os Guarani, na Universidade Estadual do Mato Grosso do Sul (UEMS), exigiram que não pedissem apenas o documento da FUNAI, mas que acrescentassem outros critérios como autodeclaração que o pai e mãe fossem indígenas, que o candidato morasse na aldeia, entre outros (CORDEIRO, 2008).

Na Universidade Federal do Pará (UFPA), o programa de reserva de vagas para povos indígenas solicita um comprovante de pertencimento da comunidade indígena emitido por autoridades políticas indígenas, caciques ou presidenres de associações indígenas que o candidato se declara pertencente (BELTRÃO; CUNHA, 2011, p. 29).

Mas como no Brasil todo mundo é índio, exceto quem não é (VIVEIROS DE CASTRO, 2005), como o "virar índio" pode trazer 
questionamentos acerca dos critérios de indianidade das comunidades indígenas que, devendo se adequar à linguagem e à formatação burocrática, produz como consequência uma inflacionamento por um lado e um esvaziamento da indianidade nativa por outro? Ou se estaria diante de um processo de inversão da cultura (SAHLINS, 1997b) em que os próprios nativos estão distorcendo a noção de indianidade para poder acessar a universidade com o objetivo de poder reexistir? O existir imbricado no sentido de resistir. É um ato de resistência dos ameríndios num país em que a presença indígena foi alvo de vários ataques de diferentes ordem para que deixasse de existir, seja fisicamente, seja simbolicamente ou ontologicamente.

Um exemplo de rexistência secular a uma guerra feroz contra eles para desexisti-los, fazê-los desaparecer, seja matando-os pura e simplesmente, seja desindianizandoos e tornando-os "cidadãos civilizados", isto é, brasileiros pobres, sem terra, sem meios de subsistência próprios, forçados a vender seus braços- seus corpos-para enriquecer os pretensos novos donos da terra. (VIVEIROS DE CASTRO, 2017, p. 192)

\subsection{Autodeclaração, Idioma da Guerra e o Acesso à Universidade}

Na Universidade Federal do Maranhão (UFMA), várias denúncias sobre a ocupação de vagas destinadas a indígenas por não indígenas já aconteciam desde o início das ações afirmativas em 20074. As lideranças indígenas realizaram diversas denúncias na universidade, na FUNAI e no Ministério Público Federal (MPF).

Em conversas com uma das minhas principais interlocutoras na pesquisa de doutorado, Maria Judite Guajajara, uma jovem tenetehara/guajajara, ela descreve as dificuldades que teve ao entrar na universidade. O primeiro curso que fez foi Comunicação Social Jornalismo no Campus de Imperatriz da UFMA. Depois, fez o vestibular para Direito em Imperatriz, mas não conseguiu entrar pelas cotas em razão de uma outra pessoa não indígena que pegou a vaga indígena. Maria conta que a vaga das cotas indígenas para o curso de Direito foi 
preenchida por uma jovem não indígena, filha de um fazendeiro antiindígena, da região de Amarante - MA. Ela, então, tentou para o curso de Direito no Campus da capital no ano seguinte conseguindo entrar.

Maria comparou a entrada na universidade na sua época - em que se solicitava o RANI para poder fazer a matrícula e se fazia uma entrevista - com a entrada, após a Lei de Cotas em 2012, que ela considera frágil. Já que se restringe à autodeclaração feita pelo próprio candidato sem comprovação.

Quando ela veio fazer sua matrícula havia esquecido na aldeia o documento e teve dificuldades em "provar" que era indígena, mesmo tendo o sobrenome Guajajara em sua identidade. Ainda assim, pondera Maria, apesar da situação delicada, havia um certo controle do Estado, que ela destaca ser positivo. Com a Lei de Cotas, sem a necessidade comprovatória da autodeclaração, qualquer pessoa pode, sem maiores problemas, entrar nas vagas indígenas, sem uma fiscalização por parte da universidade, da FUNAI ou de acompanhamento dos movimentos indígenas.

Maria aponta uma grande liderança do seu povo, José Arão Marizé Guajajara, da T.I. Bacurizinho, localizada no município de Grajaú - MA, que se preocupa com a questão do ensino superior indígena. Ele propôs (quando ainda era estudante de graduação da UFMA ${ }^{5}$ ) que os alunos indígenas se organizassem para uma mobilização na universidade em relação às ações afirmativas para os índios. Entetanto, até então, essa mobilzação dos estudantes ainda não ocorreu. A luta de José pelas vagas nas universidades ganhou mais força pelo fato de uma de suas suas filhas não ter conseguido entrar na universidade pelas cotas, pois essas vagas foram ocupadas por não indígenas. Desde então, ele passou a se mobilizar em torno dessa questão.

José fez várias denúncias sobre as ações afirmativas para índios na universidade. Em uma delas, foi ao jornal maranhense, Jornal Pequeno, expor a entrada de intrusos nas vagas para índios na UFMA. José também entrou com recurso no Ministério Público Federal denunciando violações no processo de cotas. A universidade respondeu ao jornal dizendo estar seguindo a determinação do Ministério da Educação sobre o procedimento da inscrição para o sistema de cotas, que é a autodeclaração. 
José pretende saber quem são esses índios que estão entrando, saber de onde eles vêm, qual sua origem:

Quer dizer, quem quiser ser indio que seja. Agora desde que ele conte para nós as origens dele, se a bisavó dele pelo menos passou em nossa região no Maranhão [...] mas também tem muita fraude de documento da Funai gente se passando por indígena, e agora querendo aparecer para ter acesso aos programas do governo. [...] $O$ indio pode viver 100 anos em São Luís mas ele volta para sua aldeia de origem. Agora quem nunca teve origem não volta. (José Guajajara, conversa informal, julho de 2016, grifo meu)

Os indígenas podem sair, andarem por onde quiserem, mas possuem uma origem para voltar. Mas se eles não têm origem, não há para onde voltar. Ao ter origem, o indígena se garante, esse se garantir se estabelece pelos próprios parentes. Como aponta José Guajajara "quem quiser ser índio que seja, desde que conte para nós as origens dele".

Os laços histórico-culturais com as organizações sociais pré-colombianas são evidentemente importantes, pois é bobagem imaginar que se pode definir "índio" na base do preguiçoso princípio sub-relativista segundo o qual "índio é qualquer um que achar que é". Não é qualquer um; e não basta achar ou dizer; só é índio, como eu disso, quem se garante. (Por outro lado, são sim parentes dos índios aqueles que os índios acharem que são seus parentes e ponto final, pois só os índios podem garantir isso). (VIVEIROS DE CASTRO, 2005, p. 16)

Para os índios afirmarem essa parentalidade e garantir a indianidade, há uma relação direta com uma memória, um parentesco, um território, uma origem e uma volta que estão entrelaçados. João Pacheco de Oliveira (1998) em sua reflexão sobre os índios do Nordeste, a partir da noção de índios misturados, identifica em seus discursos uma referência ao território e à memória. O autor, para retratar, imagética e poeticamente, esses dicursos cria uma figura poética "a viagem da volta" a partir dos versos de Torquato Neto.

O que a figura poética sugere é uma poderosa conexão entre o sentimento de pertencimento étnico e um lugar de origem específico, onde o indivíduo e seus componentes 
mágicos se unem e identificam com a própria terra, passado a integrar um destino comum. (OLIVEIRA, 1998, p. 64)

Além do jornal e do Ministério Público, José denunciou em todos os ambientes e espaços em que ele frequentava o que estava ocorrendo na universidade federal. Na reunião da Comissão Estadual de Articulação de Políticas Públicas para os Povos Indígenas (COEPI) ${ }^{6}$, os técnicos das secretarias de estado que estavam presentes na reunião começaram a falar sobre o levantamento que o governo estava fazendo sobre a população indígena e o atendimento das políticas de educação e saúde.

Os representantes das secretarias, ao apresentarem um levantamento quantitativo da população indígena nos municípios maranhenses, informaram que 107 municípios maranhenses possuem pessoas autodeclaradas indígenas - entretanto, sem maiores descriminações como povo ou língua. A técnica citou o exemplo do município de Araioses que possui 65 índios e 12 famílias indígenas.

Nesse momento, a liderança José Guajajara questionou a existência de índios naquela região e a relacionou com as políticas de ações afirmativas nas universidades públicas:

Isso tá acontecendo demais. Estamos com prejuízos aí. Na Universidade Federal do Maranhão estão com $90 \%$ das vagas sendo ocupada por não indio. [...] Enquanto isso, nossos parentes estão passando dificuldade, penando aqui para conseguir uma vaga, para ser um médico, um advogado, um dentista, um ensino superior da vida [...] é porque lá os bonito, os filhos de rico estão ocupando essas vagas. A gente não admite mais esse tipo de situação. [...] Agora me aparecem esses em Araioses, que eu não sei nem aonde fica, e depois vão aparecer em outros lugares, com certeza [...] Faço um pedido verbal aqui, eu quero a lista desses municípios com o nome dessas famílias que eu faço questão de fazer essa verificação in loco. (Fala pública, Reunião COEPI, julho de 2016)

José colocou essa questão, a da fiscalização e averiguação da comprovação da indianidade dos alunos, como uma tarefa da comissão. A liderança entende a questão como uma bandeira de luta do movimento indígena:

Essa é uma tarefa da comissão também, para a gente verificar como indígenas e também acionar a polícia federal para ver aonde está o erro desse negócio. Eu não vou me conformar enquanto não tiver um resultado 
para nós; a Funai também deve fazer parte desse processo, já chega do nosso nome ser envolvido em falcatruas, chegou ao fim. Se a comissão tiver que ter moralidade para algumas coisas que seja com esse procedimento. E essa é também uma bandeira de luta porque tá tudo errado. [...] passa mesmo essa lista para nós porque se for parente que venha somar com a gente se não for [....] (José Guajajara, fala pública, julho de 2016).

José aponta que os índios não devem mais permitir que seus nomes sejam envolvidos em falcatruas, ou que se fortaleça uma visão negativa acerca dos povos indígenas, pois sua indianidade está sendo manipulada por karaiw (não índios). Importante destacar que é a própria liderança que quer ir ver se tais pessoas que se identificam como indígenas são "parentes". Só é índio quem se garante. O se garantir se dá pelos pares em coletividade, pois, se forem parentes, vão somar na luta. Essa luta que se trava principalmente contra o Aparelho de Captura do Estado-nação. Uma guerra que não cessa (VIVEIROS DE CASTRO, 2017).

Outro momento em que José aciona o idioma da guerra é quando se refere ao acesso à universidade pelos índios como uma bandeira de luta a ser travada pelo movimento indígena. No evento promovido pela Licenciatura Intercultural da Universidade Estadual do Maranhão (UEMA), em janeiro de 2018, estiveram principalmente os indígenas professores que cursam a licenciatura, a FUNAI, o Centro Indigenista Missionário, o Movimento dos Sem Terra (MST), o Movimento Quilombola do Maranhão (MOQUIBOM), os professores da UEMA e os professores da UFMA e do Museu Nacional(UFRJ).

[...] Sai na imprensa, sai nos jornais, sai na Globo. Se destaca o estudante que foi melhor no Enem e a gente observa que a porta de libertação do nosso povo é, exatamente, é a educação. A gente precisa utilizar essa bandeira. Mas como é que eu vou garantir para o meu povo se eu tenho um parente que tem necessidade de fazer medicina, direito, outros cursos - e isso tem garantido na própria instituição como no caso da Universidade Federal do Maranhão, que tem sido conivente aceitando pessoas declaradamente não indígenas a ocupar vagas de indígenas na universidade federal como tem acontecido ultimamente. Então, precisa a gente ter isso como uma bandeira de luta. Porque senão aquele parente, mesmo que ele faça uma nota boa na prova do Enem, ele vai continuar sendo puxado [...] porque lá está o filho do empresário, lá está o filho de um médico, o filho de um rico ocupando 
essa vaga que poderia ser a vaga de medicina de um Canela, de um Guajajara, de um Krĩkati, um Gavião, para outros, para todo mundo. Mas infelizmente [...] nós estamos sendo prejudicados pela, por essa falta de sensibilidade e de vontade de decisão do reitor da Universidade Federal do Maranhão e nosso povo indígena está sendo prejudicado [...]. (José Guajajara, fala pública, janeiro 2018, grifos meus)

José fala para os parentes indígenas que a educação é a bandeira de luta, a porta de libertação do povo Tenetehara. Libertação em relação aos não indígenas. Uma bandeira de luta dos povos indígenas. O idioma da guerra é acionado na fala da liderança indígena. Uma guerra, pois os seus filhos e os seus parentes estão perdendo vaga, espaço e possibilidades de entrar no mundo da universidade. E porque querem entrar na universidade? Os índios não são vistos e reconhecidos em suas conquistas no mundo dos não indígenas. Os tenetehara querem mostrar aos karaiw (não índios) que eles podem estar cursando a universidade, que eles são capazes tanto quanto os brancos.

Diante da pressão indígena, em julho de 2017, a UFMA, enfim, criou uma comissão para tratar das vagas para índios na instituição. Essa comissão tinha como objetivo propor critérios que coibissem possíveis fraudes no acesso à universidade pelo sistema de cotas para índios e surgiu por orientação do Ministério Público em virtude das denúncias feitas pelos índios sobre a ocupação das vagas por não índios.

A Portaria n. 27/2017 da Pró-Reitoria de Ensino (PROEN) que institui a Comissão define como objetivo:

A realização de estudo comparativo entre as universidades federais do país no tocante aos critérios de pertencimento étnico na categoria indígena, com o intuito de construir um modelo próprio para a verificação da identidade indígena dos candidatos submetidos ao Sistema de Seleção Unificada - SISU nesta Universidade. (UFMA, 2017b)

A Comissão foi constituída por um docente do Departamento de Sociologia e Antropologia, um Técnico em Assuntos Educacionais da Divisão de Acesso à Graduação (DIAGRAD), que era o presidente da Comissão, e um assessor do setor jurídico da universidade ${ }^{7}$. O DIAGRAD é o setor responsável pelo processo seletivo do ENEM/SISU e pela 
validação de documentos específicos para a matrícula dos candidatos. Criou-se essa Comissão, cujo papel seria a criação de um modelo próprio para a verificação da autoidentificação indígena, mas em seu quadro de componentes não estavam previstos nenhuma organização indígena, nenhum estudante indígena ou representante da FUNAI.

A Comissão se constituiu de forma interna com divulgação unicamente ao Departamento de Sociologia e Antropologia, que fica localizado no Campus da capital ${ }^{8}$, e para apenas um único representante, tendo como justificativa "[...] a afinidade desse Departamento com questões pertinentes às temáticas dos povos indígenas" (UFMA, 2017b). Assim, Essa comissão desconsiderou a existência de pesquisadores sobre os povos indígenas de outras áreas de conhecimento que não se restringissem às Ciências Sociais e, ao Campus na capital, esvaziando uma possibilidade de ampla discussão no âmbito da universidade.

Após a publicação da portaria de abertura da Comissão, ela demorou ainda dois meses para se reunir. Ao se reunir, estava com os prazos atrasados em virtude de um dos membros da comissão entrar de férias logo após a publicação da portaria, que, por sua vez, fixava o prazo de 45 dias para a Comissão entregar o resultado dos seus estudos.

No primeiro encontro da Comissão, o seu presidente informou aos componentes que uma audiência pública com o Ministério Público já estava marcada, não podendo ser possível desmarcá-la. A Comissão deveria resolver os "problemas dos critérios" das vagas indígenas o quanto antes. Havia, portanto, uma "questão indígena" a ser resolvida pela instituição por meio daquela Comissão. Uma imagem recorrente na relação entre Estado e povos ameríndios, em que os índios são vistos como uma questão a ser resolvida, um problema pela sociedade não indígena (CARNEIRO DA CUNHA, 2012a)

A Pró-Reitoria de Ensino, à qual o DIAGRAD está vinculado, marcou a audiência para dar uma resposta ao MPF sem a Comissão nunca ter se reunido. A primeira reunião ocorreu no dia 5 de setembro de 2017 e a audiência foi marcada para o dia 10 de outubro de 2017.

As reuniões foram marcadas pela polarização de opiniões entre o presidente da Comissão e os professores que a compunham. De um lado, o representante da DIAGRAD preocupado em operacionalizar a 
autodeclaração indígena apontando as dificuldades da instituição em "identificar a veracidade da autodeclaração", pois, mesmo quando se identificava a "fraude", o Ministério Público não punia o candidato que agiu de má fé, punia a instituição. E, de outro lado, o discurso dos docentes que insistiam na impossibilidade de decidir qualquer critério sem antes chamar os povos indígenas e/ou suas organizações para saber como eles desejavam que deveriam ser os critérios de acesso às vagas na universidade.

Os docentes apontaram sobre a instituição estar ferindo a Convenção n. 169 da Organização Internacional do Trabalho (OIT) em relação à consulta prévia aos povos indígenas como povos interessados:

[...] consultar os povos interessados, por meio de procedimentos adequados e, em particular, de suas instituições representativas, sempre que sejam previstas medidas legislativas ou administrativas suscetíveis de afetá-los diretamente (OIT, 2011. art. $6^{\circ}$ )

De acordo com a Convenção, os povos indígenas devem ser consultados e, em particular, suas instituições representativas, por meio de procedimentos adequados em relação às medidas legislativas ou administrativas que possam vir a afetá-los diretamente. Tal procedimento não foi realizado pela universidade federal.

O edital foi publicado sem consulta à Comissão. Perguntamos se haveria possibilidade de solicitar uma errata do edital, tendo em vista a ausência do convite ao movimento indígena e a equivocada forma de inscrição: somente via e-mail e com um tempo de fala de apenas 10 minutos. Após muita insistência, decidiu-se sobre a necessidade de informar aos indígenas do edital pela própria instituição por meio de um convite, reconhecendo a dificuldade de eles terem acesso a computador, e, ainda mais, ao acesso à internet para se inscreverem em uma audiência pública na universidade.

Solicitou-se a errata que foi enviada à PROEN. Esta atendeu, em parte, ao pedido da Comissão, pois informou que iria mandar um convite às organizações indígenas. Entretanto, a forma de inscrição e o tempo não seriam alterados - uma maneira muita clara de barrar a presença dos índios em um tema referente a eles. 
Após tais negociações tensas, foi feito um convite da universidade para as organizações indígenas do Maranhão - a Coordenação das Organizações e Articulações dos Povos Indígenas do Maranhão (COAPIMA), a Associação Wyty Catë das Comunidades Timbira do Maranhão e Tocantins 9 e a FUNAI, como representante dos povos indígenas -, tomarem conhecimento da audiência pública e estarem presentes. A principal preocupação foi informar às lideranças indígenas que não havia dinheiro para trazê-las para a audiência, o que não foi questionado.

A audiência tinha como objetivo "debater e discutir os critérios de comprovação da identidade indígena na seleção ingresso para os cursos de graduação da UFMA, nos termos do presente edital"10. A universidade convidou a Fundação Nacional do Índio (FUNAI), o Ministério Público Federal (MPF), a Defensoria Pública da União (DPU) e a Procuradoria Federal junto à UFMA/AGU, os quais terão a palavra assegurada pelo prazo de 10 (dez) minutos.

Em relação às instituições indígenas e indigenistas, as inscrições seriam feitas apenas por e-mail, seis vagas foram disponibilizadas por apenas 10 minutos de fala. Em relação à comunidade acadêmica e à sociedade civil, foram disponibilizados o máximo de cinco minutos (UFMA, 2017a). As inscrições só poderiam ser feitas por um período determinado, de 25 a 27 de setembro de 2017, exclusivamente por e-mail, e só havia 10 vagas.

Realizou-se uma reunião antes da audiência pública para falar sobre ela e também sobre o relatório com os critérios de outras universidades públicas federais que fizeram adesão ao SISU. Esse levantamento foi realizado, mas foi decidido entregá-lo após a audiência e juntar os dois materiais para que a universidade tivesse, assim, uma base para poder definir seus novos critérios.

Nessa reunião, o técnico informou que apenas duas inscrições haviam sido realizadas para a audiência: um era uma liderança indígena José Guajajara e outro era uma organização indígena do povo Krĩkati. O que foi uma clara decepção para o técnico que entendeu como um não interesse por parte dos índios e de suas organizações. É preciso esclarecer que ficaria difícil de eles terem acesso à internet e a computador para a inscrição e que isso não significava desinteresse pela audiência, mas 
sim uma dificuldade da instituição em se adequar à especificidade e à diversidade das diversas realidades dos povos indígenas.

No dia da audiência, não compareceram nenhum dos dois representantes indígenas inscritos: nem a liderança e nem a organização indígena ${ }^{11}$. Entretanto, dois estudantes indígenas tenetehara/guajajara, que cursam Direito e Odontologia na UFMA, que não estavam inscritos anteriormente para a audiência compareceram.

O Pró-reitor de Assuntos Estudantis presidiu a audiência pública. Estavam presentes a Reitora, a Pró-Reitora de Ensino, os funcionários da PROAES e os funcionários da DIAGRAD. Das instituições não indígenas que estavam inscritas e que vieram, cita-se o Ministério Público, a Defensoria Pública do Estado e a Procuradoria Federal junto à UFMA. Foram abertas inscrições para quem estivesse presente na audiência. Dessa maneira, se inscreveram a FUNAI, o Conselho Indigenista Missionário (CIMI), os docentes da instituição e os estudantes indígenas tenetehara/guajajara.

A audiência teve início com a abertura feita pela Reitora enaltecendo a realização da audiência em ser "[...] uma oportunidade ímpar, na qual a opinião pública poderia discutir, sugerir, apoiar e realizar recomendações, a fim de garantir os direitos, o respeito e a cidadania às populações indígenas" (UFMA, 2017a). Em seguida, o Pró-reitor de Assuntos Estudantis continuou os trabalhos dando a palavra inicial ao chefe do DIAGRAD para que ele informasse sobre o sistema de ingresso na universidade a partir da lei de cotas. Em seguida, foi chamado para falar o Conselho Indígena Krĩkati, inscrito, porém ausente.

Então foi passada a palavra para o Procurador da República, especializado em defesa dos direitos indígenas, que relatou sobre suas experiências nos municípios de Bacabal e de Imperatriz. Este município, em particular, é localizado próximo às Terras Indígenas Krĩkati, Governador e Araribóia. A partir daí, ele apresentou o papel do Ministério Público Federal nesse debate, com o intuito de acompanhar e de contribuir a partir de experiências anteriores sobre denúncias de fraude no sistema de cotas da universidade pela FUNAI.

O Procurador investigou alguns desses casos, nos quais ouviu as pessoas que eram suspeitas de fraude por se afirmarem índios, mas que os índios não as reconheciam como tal. Ou melhor, não as garantiam. 
Diante das denúncias, o procurador chamou as pessoas para pegar depoimentos e verificar a identidade indígena dos aprovados para as vagas indígenas. Tais pessoas justificavam sua afirmação de uma indianidade por meio da existência de um parentesco indígena de bisavós que eram índias. No entanto, não sabiam qual era o povo, nem a região que viviam, e não tinham como saber mais, pois as bisavós já tinham morrido. Segundo o procurador, eram irrastreáveis as informações que as pessoas informavam a ele.

O Procurador afirmou que, em virtude dessas situações em que não se é possível rastrear as informações nem as comprovar, que apenas a autodeclaração por si não é um critério absoluto nem definitivo, sendo um equívoco da instituição pensar dessa maneira, pois a lei não é letra seca. O procurador fez uma crítica à forma como a Convenção n. 169 da OIT preconiza os direitos dos povos indígenas criando um axioma de registro absoluto no critério da autodeclaração.

Essa conotação dada pela OIT, trazida, internalizada pelo nosso direito
brasileiro, colocou, digamos, assim quase um axioma de registro
absoluto porque utiliza o critério da autodeclaração, e eu acredito, e aí
nós aqui por parte do Ministério Federal acreditamos que a leitura seca do
texto da lei, da lei que foi colocada aqui, da lei anterior lei 12.711, ela
foi infeliz. Absolutamente infeliz. Essa é a posição institucional
do Ministério Público Federal. Ela é sustentada inclusive em pareceres
e orientaçôes dadas pela $6^{a}$ Câmara de Coordenação e revisão que é o
órgão central que coordena as atividades relacionadas à defesa dos direitos
indígenas por parte do Ministério Público Federal em todo o país. E foi
dito, sim, essa redação da lei é pobre. A redação que tá no regulamento
através do decreto federal também foi pobre, porque ela não trata, ela
praticamente faz criar um novo instrumento no direito que é
uma autodeclaração com poderes absolutos. Coisa que não existe
no Direito, coisa que não existe no nosso regramento. (Audiência Pública,
10.10.2017, grifos meus)

A lei de cotas, bem como a Convenção da OIT, interpretada de forma isolada, cria um axioma de registro absoluto, uma autodeclaração com poderes absolutos, que estava sendo até então empregado pela universidade. A universidade compreendia a autodeclaração como desvinculada dos outros direitos indígenas, já garantidas na CF-88 e em documentos internacionais, de forma per si como afirma o procurador. 
No entanto, ele afirma que isso não isenta a responsabilidade do operador da lei de compreendê-la como dentro de um ornamento jurídico maior.

Ela não existe per si, por si só. Ela não é um instrumento isolado, ela está dentro de todo um conjunto de leis, de um conjunto de ordenamento jurídico que preconiza, efetivamente a garantia de que quem ocupe a cota seja uma pessoa de uma etnia indígena. (Audiência Pública, outubro de 2017, grifo meu)

É importante notar que, nessa compreensão, há um alinhamento entre o entendimento do procurador e o dos ameríndios. O inflacionamento da indianidade via autodeclaração não condizia nem com os direitos coletivos já constitucionalmente garantidos e nem com os próprios critérios nativos. O Procurador afirmou então que a UFMA tem a autonomia de criar os seus próprios critérios, e que aquele espaço se constituía como um espaço de construção de soluções sem jogar fora a autodeclaração.

Em seguida, o Defensor Público iniciou sua fala ao dizer que estava se sentindo contemplado com a fala do Procurador, sobretudo por não considerar a autodeclaração como única forma de comprovação do pertencimento a um povo indígena. Ele deu o exemplo de um concurso recente da Defensoria Pública do Estado em que, pela primeira vez, teve vagas para índios, negros e pardos, com critérios de seleção que haviam sido amplamente discutidos em âmbito nacional e com os movimentos sociais. Ele destacou o respeito pelo caráter subjetivo do pertencimento étnico-racial.

Os critérios solicitados pelo Edital n. 01-DPU, de 12 de junho de 2017, da Defensoria Pública foram uma declaração de pertencimento étnico a uma dada comunidade, com a assinatura de pelo menos duas de suas lideranças e/ou com documento da FUNAI comprovando o reconhecimento da comunidade em questão como indígena.

A Defensoria sugeriu a criação de uma comissão ou banca de verificação, a fim de averiguar, de acordo com os critérios a serem debatidos, a pertinência da autodeclaração e das justificativas apresentadas pelos candidatos. Tal comissão deveria atuar de forma que o candidato ainda pudesse interpor recursos e que também não resultasse 
em punições jurídicas aos candidatos que tivessem a impossibilidade de concorrer às vagas das ações afirmativas.

Uma banca de verificação para avaliar a pertinência da autodeclaração indígena retomou uma velha prática estadista. A questão de que quem é índio e quem não é se tornou um problema para o Estado, que, por excelência, é um gestor das identidades dos seus vassalos. Essa não é uma questão para as comunidades indígenas como analisado por Viveiros de Castro (2005, p. 13)

Com efeito e a rigor, definir quem é ou não é índio não é um problema dos índios nem de suas comunidades. Ele é um problema posto e resolvido pelo Estado, instância que trata os coletivos sob sua tutela (no sentido lato, isto é, político) dessa forma: quem é o quê, quem não é o quê, é preciso favorecer isso, desencorajar aquilo; punir, premiar, induzir, reduzir, gerir, dispor.

A terceira fala da audiência pública foi a do Procurador Federal junto à UFMA. Ele esclareceu que o papel da Procuradoria era orientar dentro dos parâmetros legais a administração da universidade sobre a questão do ingresso dos índios. Relatou sua experiência de três anos como Procurador Federal na consultoria da FUNAI e disse que, mesmo quando foi atuar com questões judiciais, continuou a prestar serviços à FUNAI. Acrescentou que naquele momento estava acompanhando a FUNAI e, ao mesmo tempo, representando a universidade, e que faria o possível para contribuir de modo que as duas instituições federais pudessem atuar de forma conjunta sobre a questão do acesso às vagas para indígenas.

Posteriormente, ele afirmou que a legislação não impõe a autodeclaração como critério único e destacou que a Convenção n. 169 da Organização Internacional do Trabalho (OIT) não menciona o termo autodeclaração, mas sim a consciência de identidade. E apresentou o seu entendimento sobre ser indígena:

Asseverou que o indivíduo que se declara indígena deve fazê-lo não porque simplesmente possui um parentesco distante, mas por possuir um vínculo cultural, sob pena de tornar-se um quotista que não proporcionará contribuições efetivas à sociedade e aos povos indígenas. Por isso, haveria 
de se discutir os critérios realmente capazes de ampliar o acesso justo de indígenas à UFMA. (UFMA, 2017a, p. 4)

O Procurador realiza uma equiparação entre as definições postas pela Convenção n. 169 da OIT (2011) e a definição afirmada pelo Decreto n. 5.051, de 19 de abril de 2004, que promulga a Convenção n. 169. A primeira afirma que a “[...] autoidentificação como indígena ou tribal deve ser considerado como critério fundamental para definição dos grupos" (OIT, 2011, artigo $1^{\circ} \S 2$ ). Já o Decreto n. 5.051/2004, que promulga a Convenção n. 169 no Brasil, utiliza-se a expressão "consciência de sua identidade indígena ou tribal". O Procurador em sua fala equipara a autodeclaração à consciência da identidade indígena.

As definições dos documentos relacionam as autoidentificações ao grupo reconhecendo e reforçando o direito coletivo dos povos nativos. Como afirma Viveiros de Castro (2005, p. 14), a indianidade está diretamente relacionada a um coletivo e não pode ser pensada de forma individualizada, "Nesse sentido não existem índios, apenas comunidades, redes (d)e relações que se podem chamar indígenas".

Ao final de sua intervenção foi chamada a única liderança indígena que conseguiu se inscrever, José Guajajara, mas que não compareceu. Foram também chamadas as representantes da FUNAI: a primeira delas, advogada, que trabalhava na coordenação de processos educativos. Ela comentou sobre uma reunião que ocorrera em maio de 2015, a qual tratou da identidade indígena e o acesso às cotas, na qual a universidade se responsabilizava em ampliar a discussão. Ela entendia que aquela audiência era um dos efeitos dessa reunião.

A advogada da FUNAI relembrou que, naquele encontro, conversou com a universidade sobre a questão das ações afirmativas e sobre as denúncias dos índios. Afirmou que desde então viu as alterações que a UFMA fez como palestras sobre as ações afirmativas e a mudança no edital, com a retificação da declaração indígena. Alegou, ainda, que a Lei de Cotas reúne várias especificidades, mas que não se poderia perder de vista a base legal dos direitos dos índios, o seu estatuto e a própria Constituição Federal. Além disso, afirmou não haver impedimento legal para se aplicar outros critérios de acesso às cotas dos índios, já que a universidade tem autonomia de estabelecer outros parâmetros. 
Assim, como o Procurador e o Defensor Público, a representante da FUNAI falou sobre a não especificidade da Lei de Cotas, bem como sobre a impossibilidade de entendê-la de forma isolada, ou mesmo esquecendo o conjunto de legislação sobre os povos indígenas, inclusive a própria Constituição. A representante da FUNAI enfatizou que o índio, independentemente de onde esteja, tem o vínculo com a comunidade e sabe da história, do movimento indígena, tem a sua especificidade étnica. Esse conjunto de elementos constitutivos da indianidade poderia ser exigido para preenchimento das cotas.

Como afirma Baniwa (2006, p. 167) sobre a questão política da autodeclaração de forma individualizada, como um projeto ou diretriz individual, é inadequado para se pensar sobre os povos indígenas, pois a referência para a identificação das ações afirmativas na universidade deveria ser as comunidades indígenas.

Neste caso, as coletividades (aldeias, comunidades, povos e organizações indígenas) deveriam ser as referências para a identificação dos estudantes, com toda a complexidade que isso implica. Interessante neste caso é que não são os não-índios (mesmo com representação indígena) que decidem pelos índios, mas os próprios índios. Penso que o maior problema não é o mais correto moral, científica ou tecnicamente, mas sim o mais legítimo. A decisão legítima das comunidades para identificarem ou até indicarem seus candidatos não pressupõe negar o papel das técnicas, as quais podem subsidiar e qualificar os critérios de decisões das coletividades sem anularem a autonomia dos grupos. (BANIWA, 2006, p. 167, grifos meus)

Essa relação entre a técnica, como aponta Baniwa, e as decisões das comunidades se inicia nesse processo tenso entre as demandas dos povos indígenas, em particular, os tenetehera/guajajara, e a UFMA, mediada por algumas instituições - que de alguma forma assumem o papel de indigenistas -, que se pode entender como uma tentativa em construção de atender aos critérios das comunidades sem anular a autonomia deles.

A outra representante da FUNAI, a coordenadora regional, teve a palavra em seguida. Reafirmou a ideia de que apenas a autodeclaração 
como critério era insuficiente para o acesso às cotas e que os índios de Imperatriz reclamavam desse método da universidade, pois já haviam constatado fraudes nesse sistema. Manifestou a ideia de que apenas duas assinaturas, como proposto pela Defensoria Pública, não eram suficientes, pois, nas comunidades indígenas, havia muitas lideranças que eram capazes de identificar seus membros, como os caciques, os pajés e os professores.

Na sequência, teve a palavra a representante do Conselho Indigenista Missionário (CIMI) que destacou a dívida imensa que se tem com os povos indígenas em relação à educação. Ela expressou a vontade de vários povos indígenas de estarem na audiência, mas que não puderam comparecer.

A representante do CIMI defendeu a posição da FUNAI de não emitir documentos de comprovação de identidade indígena, e sim que os próprios povos indígenas que deveriam tomar as suas decisões. Ela salientou que a Universidade Estadual do Maranhão (UEMA) estava ofertando uma licenciatura intercultural e questionou porque a Universidade Federal ainda não havia feito o mesmo.

Ao final da fala do CIMI, o Defensor Público esclareceu as críticas que recebeu da FUNAI e do CIMI afirmando que eles não solicitaram a emissão de declaração de comprovação de pertencimento étnico pela FUNAI e que seriam pelo menos duas declarações assinadas pelas lideranças indígenas. Eles estabeleciam um mínimo, mas não tinha um número máximo de declarações.

Depois das retificações apresentadas, o presidente da audiência perguntou à plateia se alguém gostaria de se manifestar. O estudante indígena Inaw'y Carneiro Guajajara ${ }^{12}$ pediu a palavra. Se identificou como aluno da universidade e da região de Barra do Corda - MA. Agradeceu pela realização daquela audiência, classificando-a como muito importante, pois há muito tempo os índios e as lideranças indígenas reclamavam sobre a dificuldade em entrar na universidade:

Eu mesmo, em 2009, aconteceu que eu fui o terceiro suplente para a vaga de medicina, era na época que admitia a pessoa que era cadastrada em qualquer tipo de situação no Sisu, tanto ela ser negra, indigena e deficiência ela podia colocar em qualquer vaga e concorrer até o último dia. Aí, no final, as pessoas apareceram e a universidade, no momento, 
colocou minha vaga para a geral e não apareceu nenhum indígena para se inscrever e eu fui procurar a defensoria pública, só que sem condições de me manter aqui em São Luís, para correr atrás disso acabei voltando para a minha região. (Inaw'y Carneiro Pompeu Guajajara, audiência pública, outubro de 2017)

Inaw'y relatou como o processo de autodeclaração não garante que ele como indígena conseguisse entrar na universidade. As vagas eram preenchidas, mas nenhum parente entrava na universidade. Para ele, a criação de uma comissão seria muito importante para poder verificar quem seria indígena, mas trabalhando em conjunto com as entidades dos movimentos indígenas:

A formação dessa comissão, para auxiliar na verificação dos indígenas que vão ocupar essas vagas, é extremamente importante. Porque a Funai é a entidade que tá aqui para a ajudar a nós indígenas, mas só que todo mundo está vulnerável a erros, né? E o mais importante ainda é que essa comissão possa ser formada, que ela atue bem próximo com as entidades que lutam em prol das políticas indigenistas como a Coapima, a Coiab ${ }^{13}$, e a Apib ${ }^{14}$. (Inaw'y Carneiro Pompeu Guajajara, audiência pública, outubro de 2017)

Para Inaw'y, a comissão deveria ser constituída por essa articulação entre a FUNAI - ainda vista como o órgão indigenista por excelência - e as entidades que lutam pelos povos indígenas, já que são vistas como instituições representantes dos indígenas, o que também pode gerar uma série de questionamentos sobre a própria noção de representatividade e os coletivos indígenas (uma reflexão que fugiria dos limites do presente artigo).

Outro aspecto destacado por Inaw'y é a diferença e a desigualdade entre as escolas da aldeia e as escolas não indígenas. O impedimento de acessar a vaga na universidade reservada para os indígenas por outros é mais uma agressão, uma violência sofrida pelos tenetehera/guajajara.

Assim, a autodeclaração de que quem chega aqui e se autointitula indígena simplesmente em prol desse direito, eu trato isso como uma agressão. É, é [...] Uma agressão aos povos indígenas porque, vejamos bem, tem alguém da educação do estado? enfim [...] de forma que é impossivel ter um grau de competitividade com a pessoa que se autodeclara indígena, como falado aqui, que mora numa cidade e tem toda uma estrutura. (Audiência Pública, outubro de 2017) 
Inaw'y aponta a necessidade de "melhorar" a educação nas aldeias e averiguar os casos das pessoas que estão entrando nas vagas para indígenas na universidade como duas formas de melhorar o direito à educação para os índios. Assim como o Inaw'y, Maria Guajajara possui a mesma posição sobre a relação entre a educação básica nas aldeias e o ensino superior. Ela destaca que, sobretudo para os índios que tiveram uma educação básica de má qualidade e sem recursos para se manter estudando, é difícil entrar no ensino superior. Para ela, se nas aldeias tivesse uma educação de qualidade, as ações afirmativas não mais seriam necessárias para os índios.

As comunidades indígenas não têm a oportunidade de se preparar para o vestibular, não têm a oportunidade de [...] vamos dizer, de tentar dar um passo pra compreender um mundo que tá diferente, meio que tá engolindo a gente. Então a saída que a gente vê, o primeiro passo, é a universidade. Porque, querendo ou não, a gente vê a universidade como onde a gente vai aprender, vai abrir nossa visão, vai $[\ldots]$ o melhor espaço, a melhor oportunidade que os indígenas têm para compreender, apesar de suas dificuldades, é a universidade. E enquanto não tivermos uma educação de qualidade que prepare realmente os jovens indígenas, não só jovens, mas qualquer um que queira entrar na universidade para concorrer de igual, são necessárias as cotas, entendeu? ${ }^{15}$

Na concepção dos jovens tenetehara, a educação na aldeia não os prepara para a entrada na universidade. Por isso, as cotas, que seriam um caminho de entrada, devem ser acompanhadas pelo movimento indígena para garantir a entrada dos parentes. Uma questão que surge como desdobramento é: como garantir que a educação na aldeia continue respeitando à diferenciação dos processos educacionais nativos e, ao mesmo tempo, possa contribuir para que os jovens indígenas que queiram entrar na ensino superior estejam preparados para esse choque cultural e educacional? São questões que em suas falas os alunos tenetehara/guajajara colocam diante desse cenário.

Em seguida, falou o seu irmão Pinauê, que estava presente na audiência. Ele falou sobre a diferença muito clara em quem se autodeclara índio ser sem índio: o pensar em si próprio.

E a gente se sente lesionado nisso porque o que mais os povos indígenas esperam da gente é que [...] a gente que consegue com muita luta entrar em um curso federal, um curso como esse, é que a gente volte para a 
nossa terra e o que a gente conquistou que a gente leve para eles. Porque lá realmente não tem essas questões que eles se autodeclaram, elas vão se [...] estão ali buscando o seu próprio benefício, infelizmente elas vão buscar o seu retorno financeiro para si próprio, estão pensando em si próprio. A gente que vem para cá para voltar para as suas terras, voltar para os seus parentes. (Pinauê Guajajara, fala pública, outubro de 2017)

O egoísmo e o individualismo dos não índios em comparação ao pensamento voltado para o coletivo é o que diferencia um Teneteharade de um karaiw como apontou o Pinauê. Os Tenetehara estudam para voltar para a terra, para os seus parentes. Como também já havia relatado a jovem Maria Guajajara. A ideia da volta novamente é marcada no discurso dos tenetehara/guajajara. O sair da sua comunidade em busca de novos conhecimentos, mas sabendo que irá voltar para sua aldeias, seu povo. "Quem não tem origem não tem volta".

Pinauê relata que ja foi procurado por pessoas não indígenas para que ele conseguisse uma carta assinada pelo cacique para a admissão na universidade. Para ele, a autodeclaração pode conter um caráter individualista da forma como está sendo usada atualmente, permitindo que fraudes aconteçam. Coadunando com o mesmo entendimento, Baniwa (2013, p. 19) caracteriza a autodeclaração como individualista e diz que, por consequência, negaria a autonomia coletiva dos povos indígenas.

Considerando as experiências atuais, não existe algo tão individualista quanto o princípio da autodeclaração, pois ele nega totalmente a autonomia coletiva dos povos indígenas. Entendemos que o princípio da autodeclaração tem sua relevância, mas não pode ser a única forma de identificação étnica. Deveria ser associada a outros instrumentos de declaração ou identificação, como de pertencimento etnoterritorial ainda que como memória histórica, linguística e o reconhecimento de seu povo de pertencimento. (BANIWA, 2013, p. 19)

Como defende Baniwa (2013), o empedimento do uso individualista da autodeclaração ocorreria por meio da combinação com outros intrumentos de identificação em diálogo com as comunidades indígenas. Tal modelo já é executado por outras universidades federais, por exemplo, a UFPA. Beltrão e Cunha (2011) analisam a experiência 
das ações afirmativas para índios nesta universidade, destacando a preocupação dessa instituição em garantir o respeito ao caráter coletivo e à autonomia dos povos nativos. O caráter coletivo da ação afirmativa estaria sendo contemplado na medida em que o benefício não é dirigido apenas ao indígena/estudante, e sim ao grupo, que valida a inscrição dos seus integrantes por meio do documento de pertença. Assim, o edital de seleção para as vagas reservadas, ao abraçar a pertença étnica como critério fundamental, está vislumbrando a necessidade de tal política beneficiar não somente um indivíduo, mas o grupo ao qual ele pertence (BELTRÃO; CUNHA, 2011, p. 31)

No final da audiência, uma liderança indígena Guajajara entrou em contato comigo para saber o que estava acontecendo e quem estava lá representando os povos indígenas e o movimento indígena. Falei para Cintia Guajajara, tia de Maria, que infelizmente os representantes indígenas não compareceram, mas que dois Guajajara que estudam na universidade falaram sobre suas experiências e colocaram as dificuldades que os parentes têm para ter acesso às vagas na universidade. Cintia disse que estava mais tranquila em saber que o povo Tenetehara estavam bem representado por jovens Guajajara na audiência.

Ela agradeceu e repassou essa informação aos outros grupos. Dias depois na aldeia Lagoa Quieta, onde Cintia mora, ela me explicou que os parentes a estavam cobrando, em virtude de ela ser uma das lideranças que atuam na área da educação e não estava presente na audiência. Ela disse que não pôde ir porque não tinha recurso para o deslocamento até São Luís e depois voltar para a aldeia. Quando Cintia disse que dois jovens Guajajara falaram na audiência, os parentes ficaram menos chateados.

Maria também me relatou que foi cobrada por não ter ido à audiência pública. Tanto por parentes quanto por parceiros que acompanham o movimento indígena, como o CIMI. Maria respondeu que ela já tinha feito a parte dela durante a sua graduação, mas agora que ela já tinha terminado o curso, era hora de outros parentes entrarem e fazerem sua parte nesta luta.

Destacou-se, na fala de todos que participaram da audiência, em especial, dos jovens tenetehara/guajajara, a necessidade da criação de 
uma comissão para acompanhar a entrada das vagas indígenas; verificar a documentação dos candidatos e, principalmente, se manter em diálogo com as instituições de movimento indígena ${ }^{16} \mathrm{e} / \mathrm{ou}$ ter membros indígenas na comissão. Todas as sugestões foram encaminhadas à PróReitoria de Ensino (PROEN) para a decisão sobre os critérios para as vagas para indígenas por meio de um relatório final.

Posteriormente, a universidade criou comissões definitivas em todos os campi para atuar na verificação documental da autodeclaração de acordo com as exigências das comunidades indígenas em parceria com a FUNAI, isto é, uma declaração de pertencimento étnico-indígena assinada por pelo menos duas lideranças indígenas, uma entrevista com a Comissão composta de docentes e técnicos em parceria com a FUNAI para comprovação da documentação com as lideranças das respectivas comunidades indígenas ${ }^{17}$. Atualmente, essa é uma situação que ainda está em andamento, com fortes tensionamentos na universidade, mas sendo observada atentamente pelas lideranças indígenas.

\subsection{A Lei de Cotas e o Combate à Noção de Transitoriedade pelos Ameríndios}

A luta pelo acesso ao ensino superior se dar tanto pela garantia da entrada quanto pela propria manutenção das ações afirmativas para os povos nativos. A ideia de transitoriedade permeia as políticas de ação afirmativa, que têm como objetivo, após um determinado período, depois de cumprirem seu propósito de inclusão, não mais existirem. Essa políticas não seriam mais necessárias, uma vez que as diferenças, entendidas na chave da desigualdade, seriam "reparadas" e desapareceriam. Ocorrendo, enfim, uma inclusão dos excluídos. Na lei de cotas está estabelecido o prazo de dez anos, a contar da data da plublicação, para uma revisão da ação afirmativa que findará em 2022.

Em relação aos índios, as políticas indigenistas foram marcadas pelo seu caráter temporário, já que os povos indígenas, alvo daquelas ações do Estado, logo iriam se transformar em civilizados, trabalhadores, brancos e, por fim, desapareceriam em sua diferença ontológica.

A antropóloga Coelho de Souza (2017), em sua análise sobre as ações afirmativas para os índios, identifica que o direito deles à educação 
diferenciada implica a impossibilidade de interpretar sua diferença como transitória. A perspectiva da transitoriedade das ações afirmativas traz em si os horizontes da aculturação ou da mestiçagem, qual seja, um horizonte epistemicida. No entanto, a garantia constitucional do direito à educação diferenciada bloquearia esse horizonte.

Os estudantes indígenas sempre chegarão (idealmente) de uma trajetória escolar diferenciada - não pode haver prazo para estas cotas, se é que poderá haver para alguma. Este é um dos aspectos, aliás, em que a especificidade do caso indígena talvez permita ver algo que tende a ficar oculto, mas que nem por isso está ausente: o quanto a perspectiva da transitoriedade das ações afirmativas parece supor os horizontes da aculturação ou da mestiçagem, isto é, uma subsunção da diferença que é ao mesmo tempo o ocultamento da violência que contra ela se dirige. [...]. (SOUZA, 2017, p. 103)

Essa ideia de uma transitoriedade dos povos indígenas é combatida cotidianamente pelos índios, pelo movimento indígena, principalmente, por meio da cultura. Uma rexistência cultural que já existe há mais de 500 anos, como afirma a liderança José Guajajara, e que está sendo mantida atualmente pelos jovens, devendo os professores indígenas também atuarem nesse processo.

São jovens que estão aí incentivando a prática da cultura e isso tem que se perpetuar. Se a gente conseguiu resistir por mais de trezentos, de quinhentos anos a gente tem a obrigação de continuar com esse trabalho. Porque japonês, mexicano, italiano e espanhol e governo brasileiro não vai levar isso para a sala de aula, se não for através de nós que somos professores. (José Marizé, fala pública, 02/1/2018)

O ato de existir do povo Tenetehara já é em si um ato de rexistência como aponta Viveiros de Castro (2017). A existência dos povos indígenas é por si só uma rexistência cultural, simbólica e física contra o processo imposto de desindianização feito pelo Estado brasileiro.

A ação de resistir pela educação, seja escolar, seja universitária, está presente também entre os Kaiowá, como analisado pelo antropólogo Santos (2016, p. 206), tomando como base o pensamento do antropólogo Eliel Benites. A noção de resistência traz em si, intrínseca a ela, uma abertura ao outro, uma experimentação com setores do mundo colonial 
que constrói espaços e fronteiras nos quais a dominação é subvertida.

Os índios como coletivos não vão deixar de ser quem eles são, pois o processo de desindianização nunca foi concluído (e nem será!), eles não podem ter um direito à difença pautado no princípio de que em alguns anos estarão no mesmo patamar meritocrático dos não indígenas. Dessa forma, não deve existir um prazo de validade para as ações afirmativas aos povos ameríndios.

Por que o prazo de dez anos para revisão da lei de cotas em sua execução? Diante de um processo de mais de 500 anos de exploração, tentativas de extermínio, escravização e mestiçagem forçada, por que não mais outros 500 anos de reserva de vagas?

Essa relação de tensão entre a tentativa do estado de invisibilização e dos ameríndios de se manterem existindo é a continuação de uma guerra ontológica, epistemológica. A rexistência, como uma estratégia de guerra, é o recurso final para que eles sejam ouvidos (VIVEIROS DE CASTRO, 2017).

\section{Considerações Finais}

A lei de cotas estabelece como critério principal a autodeclaração dos índios para ocupação das vagas nas universidades públicas. A autodeclaração como um direito se torna uma questão a ser debatida nos espaços universitários acerca da indianidade, não pelos índios, mas sim pela universidade. Para os ameríndios, a indianidade é compreendida por estar vinculada a uma memória, a uma história, a uma luta contra a desindianização imposta pelo Estado, a uma volta, como foi apontado em várias falas dos tenetehara/guajajara sobre a sua ligação com a terra, com a comunidade, com os parentes. Um indígena possui uma origem, um pertencimento para poder voltar. Quem não é índio não tem esse vetor do retorno.

Diante desse embate, coloca-se uma questão central, entre tantas: como garantir o direito à autodeclaração respeitando os critérios coletivos das comunidades e não a imposição violenta de um princípio dissociado dos povos? O respeito à diferença pode se transformar em uma homogeneização por parte do Estado e sua lógica burocrática como analisada acima. Os indígenas estão lutando contra 
essa homogeneização indiferenciada. Uma homogeneização que os apaga, que os invisibiliza, que os entende como transitórios, assim como as próprias ações afirmativas para índios, que possuem como princípio a noção de transitoriedade.

Nesse novo conflito com o Estado, o Uno por excelência, como afirma Clastres (2013), o idioma da guerra é acionado pelos ameríndios. Os ameríndios se colocam nesse debate com o intuito de garantir um espaço no ensino superior como uma rexistência pelo direito de existirem e de continuarem a ser quem são, independentemente de desejarem os saberes do não índio. Como afirmam as lideranças indígenas tenetehara, lutar pela universidade para que possam continuar a ser tenetehara.

\section{Notas}

1 O povo Tenetehara, também conhecido como Guajajara, é um povo falante da língua materna de mesmo nome classificada na família linguística Tupi-Guarani e do português. Os tenetehara possuem uma população estimada em 27.616 pessoas, segundo dados da Secretária Especial de Saúde Indígena (SESAI apud ISA, 2020). Eles vivem localizados no Estado do Maranhão em 11 terras indígenas.

2 Existiam duas modalidades principais de acesso ao ensino superior que caracterizavam as ações afirmativas para os povos indígenas no Brasil antes da Lei de Cotas n. 12.711 de 2012 (SANTOS, 2016). Em 2001, se iniciou uma ação afirmativa de acesso diferenciado aos povos indígenas nas universidades estaduais do Paraná, por meio de vagas suplementares (PAULINO, 2008). E também houve a criação do primeiro curso de Licenciatura Intercultural para professores indígenas ofertado pela Universidade Estadual do Mato Grosso (UNEMAT).

3 Vários estudos refletem sobre os sentidos da "fraude" nas cotas para indígenas, vale destacar o trabalho de Cunha e Beltrão (2012).

4 A UFMA instituiu as vagas para negros, deficientes e índios em 2007. Nesse momento, os candidatos às vagas para negros e "índios" levavam os documentos pessoais, o RANI, e faziam uma entrevista com a Comissão de Verificação para as vagas reservadas para negros e índios, formada por docentes e técnicos. Os candidatos às vagas para deficientes passavam, e ainda passam, por uma comissão médica. Para maior aprofundamento, ver Maciel (2009).

5 Maria Judite defendeu o mestrado em Direito na Universidade de Brasília (UNB).

6 A COEPI tinha como objetivo construir uma política pública estadual para os povos indígenas. Ela teve início em julho de 2016 e finalizou os trabalhos em novembro de 2017. Em 14 de novembro de 2018 foi sancionado o Decreto n. 34,557, que institui o plano decenal estadual de políticas públicas voltadas para os povos indígenas no Maranhão.

7 Como docente da instituição, solicitei à PROEN um pedido para poder participar da Comissão, em virtude do tema da minha pesquisa de doutorado, sendo prontamente autorizado. Pude participar como colaboradora por estar afastada para o doutorado, mas não foi possível incluir meu nome na portaria. 
8 A UFMA possui desde 2010 nove Campi distribuídos no estado.

9 Associação dos povos Timbira do Maranhão e Tocantins tem o intuito de se relacionar com as instituições da sociedade nacional em assuntos como educação, saúde, conservação ambiental e outros assuntos de relevância aos povos Timbira.

${ }^{10}$ Edital n. 158/2017 PROEN.

${ }^{11}$ A liderança Tenetehara José da T.I. Bacurizinho, posteriormente me informou que não pôde comparecer à audiência porque estava em uma caçada para a Festa da Menina Moça que iria ter em sua aldeia. As lideranças da organização indígena dos Krĩkati informaram não ter conseguido recursos para irem a São Luís participar da audiência.

12 Inaw'y é filho da liderança Caci. Ela é casada com um tenetehara e luta pelo direito dos povos indígenas. A comunidade a reconhece como liderança. Seus filhos Inaw'ye e Pinauê estão na UFMA. Sua filha Inaiury está cursando a Licenciatura Intercultural da Universidade Estadual do Maranhão (UEMA).

${ }^{13}$ Coordenação das Organizações Indígenas da Amazônia Brasileira (COIAB) foi criada em uma reunião de líderes indígenas em abril de 1989.

14 APIB - Articulação dos Povos Indígenas do Brasil -, é uma associação nacional de entidades que representam os povos indígenas do Brasil, criada em 2005.

15 Entrevista concedida por Maria. Entrevistadora: Autora. São Luís, maio 2015.

${ }^{16}$ O que começou a ocorrer a partir de 2018.2.

17 Em julho de 2019, a FUNAI se retirou da parceria com a universidade, pois o setor jurídico da instituição considerou que a atuação da FUNAI estava ferindo a autonomia dos povos indígenas. O que provocou outras configurações na composição e na atuação da comissão.

\section{Referências}

BANIWA, Gersem José dos Santos Luciano. A Lei de Cotas e os povos indígenas: mais um desafio para a diversidade. In: Cadernos do Pensamento Crítico Latino-Americano. Revista Fórum, [S.l.], [p. 18-21], jan. 2013.

BANIWA, Gersem José dos Santos Luciano. O índio brasileiro: o que você precisa saber sobre os povos indígenas no Brasil. Brasília: Ministério da Educação, Secretaria de Educação Continuada, Alfabetização e Diversidade; LACED/Museu Nacional, 2006.

BELTRÃO, Jane Felipe; CUNHA, Mainá Jailson Sampaio. Resposta à diversidade: políticas afirmativas para povos tradicionais, a experiência da Universidade Federal do Pará. Espaço Ameríndio, Porto Alegre, v. 5, n. 3 , p. 10-38, jul.-dez. 2011.

BRASIL. Decreto n. 5.051, de 19 de abril de 2004. Promulga a Convenção n. 169 da Organização Internacional do Trabalho (OIT) sobre povos indígenas e tribais. [2004].

BRASIL. Constituição Federal de 1988. 34. ed. Brasília, DF: Edições Câmara, 2011. 
BRASIL. Lei n. 12.711, de 29 de agosto de 2012. Dispõe sobre o ingresso nas universidades federais e nas instancias federais de ensino técnico e de nível médio e dá outras providencias. Brasília, 2012. Disponível em: http:// www.planalto.gov.br/ccivil_03/_ato2011-2014/2012/lei/112711.htm. Acesso em: 5 dez. 2012.

CARNEIRO DA CUNHA, Manuela. "Cultura" e cultura: conhecimentos tradicionais e direitos intelectuais. In: CARNEIRO DA CUNHA, Manuela. Cultura com aspas. São Paulo: Cosac Naify, 2009. p. 311-373.

CARNEIRO DA CUNHA, Manuela. O futuro da questão indígena. In: CARNEIRO DA CUNHA, Manuela. Índios no Brasil: história, direitos e cidadania. São Paulo: Claro Enigma, 2012a. p. 118-139.

CARNEIRO DA CUNHA, Manuela. Questões suscitadas pelo conhecimento tradicional. Revista de Antropologia, São Paulo, USP, v. 55, n. 1, p. 439-459, 2012b.

CLASTRES, Pierre. A sociedade contra o Estado. In: CLASTRES, Pierre. Sociedade contra o Estado. São Paulo: Cosac Naify Portátil, 2013. p. 99- 126.

COELHO SOUZA, Marcela Stockler. Contradisciplina: indígenas na pósgraduação e os futuros da antropologia. Rev. Antropol., São Paulo: USP, v. 60, n. 1, p. 99-116, 2017.

CORDEIRO, Maria José de Jesus Alves. Negros e indígenas cotistas da Universidade Estadual de Mato Grosso do Sul: desempenho acadêmico do ingresso à conclusão de curso. 2008. 260f. Tese (Doutorado em Educação-Currículo) - Pontifícia Universidade Católica de São Paulo, São Paulo, 2008.

CUNHA, Mainá Jailson Sampaio; BELTRÃO,Jane Felipe. Povos indígenas, universidade e programa de reserva de vagas: implantação e tentativas de fraude. Belém/PA:UFPA, 2012. Monografia (Bacharelado em Direito) - Faculdade de Direito, Universidade Federal do Pará, 2012.

ISA - INSTITUTO SOCIOAMBIENTAL. Verbete Guajajara. [2020]. Disponível em: https://pib.socioambiental.org/pt/Povo:Guajajara. Acesso em: 10 ago. 2020.

MACIEL, Regimeire Oliveira. Ações afirmativas e universidade: uma discussão do sistema de cotas da UFMA. 2009. 138f. Dissertação (Mestrado em Ciências Sociais) - Pontifícia Universidade Católica de São Paulo, São Paulo, 2009.

MARANHÃO. Decreto n. 34.557, de 14 de novembro de 2018. Institui o Plano Decenal Estadual de Políticas Públicas voltadas para os Povos Indígenas no Maranhão-PPPI. [2018]. 
OIT - ORGANIZAÇÃO INTERNACIONAL DO TRABALHO. Convenção Internacional do Trabalho $\mathbf{n} .169$ sobre povos indígenas e tribais Resolução referente à ação da OIT. Brasília: OIT, 2011.

OLIVEIRA, Ana Caroline Amorim. A Caneta é nossa borduna: um estudo etnográfico sobre as experiências indígenas Tenetehara/Guajajara no ensino superior no Maranhão. 2018. 234f. Tese (Doutorado em Antropologia Social) - Universidade de São Paulo, São Paulo, 2018.

OLIVEIRA, João Pacheco de. Uma etnologia dos "índios misturados"? Situação colonial, territorialização e fluxos culturais. Mana, Rio de Janeiro, v. 4, n. 1, p. 47-77, 1998.

PAULINO, Marcos Moreira. Povos indígenas e ações afirmativas: o caso do Paraná. 2008. 162f. Dissertação (Mestrado em Educação) Universidade Federal do Rio de Janeiro, UFRJ, Rio de Janeiro, 2008.

SAHLINS, Marshall. O "pessimismo sentimental" e a experiência etnográfica: porque a cultura não é um "objeto" em vias de extinção (parte 1). Mana, Rio de Janeiro, v. 3, n. 1, p. 41-73, 1997a.

SAHLINS, Marshall. O "pessimismo sentimental" e a experiência etnográfica: porque a cultura não é um "objeto" em vias de extinção (parte 2). Mana, Rio de Janeiro, v. 3, n. 2, p. 103-150, 1997b.

SANTOS, Augusto Ventura. Políticas Afirmativas no Ensino Superior: estudo etnográfico de experiências indígenas em universidades do Mato Grosso do Sul (Terena e Kaiowá-Guarani). 2016. 223f. Dissertação (Mestrado em Antropologia Social) - Universidade de São Paulo, São Paulo, 2016.

SOUSA, Josicélia do Nascimento Ramos. Os desafios dos estudantes e das instituições no convênio Funai-UnB. 2009. 85f. Monografia (Graduação) - Universidade de Brasília, Brasília, 2009.

UFMA - UNIVERSIDADE FEDERAL DO MARANHÃO. Resolução n. 677 do CONSEPE, de 30 de abril de 2009. Efetiva a adesão da UFMA ao Sistema Nacional Unificado de Seleção para ingresso no Ensino Superior (MEC/INEP/NOVO ENEM) como critério exclusivo de acesso aos seus cursos de graduação, e dá outras providências. [2009].

UFMA - UNIVERSIDADE FEDERAL DO MARANHÃO. Ata da audiência pública sobre o acesso de cotistas indígenas aos cursos da UFMA. 10 de outubro de 2017. Auditório da Pró-reitoria de Pesquisa e Pósgraduação e Inovação - PPPGI. São Luís: UFMA, 2017a.

UFMA - UNIVERSIDADE FEDERAL DO MARANHÃO. Portaria n.

27/2017. Pró-Reitoria de Ensino. Institui a Comissão para criação de vagas para indígenas na universidade. [2017b]. 
UFMA - UNIVERSIDADE FEDERAL DO MARANHÃO. Edital n. 158/2017. Convocação de audiência pública para discussão dos critérios de comprovação da identidade indígena na seleção ingresso para os cursos de graduação. [2017c].

VIVEIROS DE CASTRO, Eduardo. Todo mundo é índio exceto quem não é. Povos Indígenas no Brasil. São Paulo: Instituto Socioambiental, 2005.

VIVEIROS DE CASTRO. Os involuntários da pátria. Aula pública durante o Abril Indígena, Cinelândia, Rio de Janeiro, 20/4/2016. ARACÊE - Direitos Humanos em Revista, [S.l.], Ano 4, n. 5, fev. 2017.

Recebido em: 19/08/2019

Aceito em: 16/01/2020

\section{Ana Caroline Amorim Oliveira}

Professor Adjunto II de Sociologia da Universidade Federal do Maranhão (UFMA), lotada no Curso de Licenciatura em Ciências Humanas/Sociologia do Campus São Bernardo. Professora Permanente do Programa de Pós-Graduação em Cultura e Sociedade-Pgcult (UFMA) na linha de pesquisa Expressões e Processos Socioculturais. Líder do Grupo de Pesquisa Epistemologia da Antropologia, Etnologia e Política (CNPQ).

Endereço profissional: Campus São Bernardo, Rua Projetada, s/n, Bairro Planalto, São Bernardo, MA. CEP: 65.550-000.

E-mail: ana.caroline.oliveira@gmail.com 